\title{
Ring Opening of Azabicyclic Alkenes Co- Catalyzed by Palladium and Copper
}

Metal-Catalyzed Asymmetric

Synthesis and Stereoselective Reactions

\section{Key words}

desymmetrization

asymmetric ring opening

\section{palladium}

copper

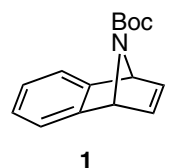

(1.0 equiv)

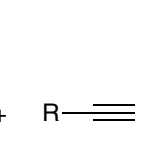

2

(5.0 equiv)
(R)-xyl-BINAP $(6 \mathrm{~mol} \%)$

CuOTf (10 mol\%)

DME, $0^{\circ} \mathrm{C}$

$0.2 \mathrm{mmol} \mathrm{scale}$

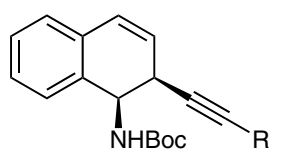

up to $98 \%$ yield up to $>99.9 \%$ ee

Proposed mechanism:

$\mathrm{H}^{+}$<smiles>CC(C)(C)OC(=O)N(Cl)C1c2ccccc2C=CC1C#CF</smiles>

$\mathrm{Pd}(\mathrm{OAc})_{2}$

(R)-xyl-BINAP

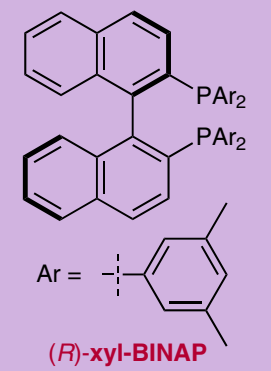

$\mathrm{Boc}^{-}{ }^{-} \mathrm{Cu}$

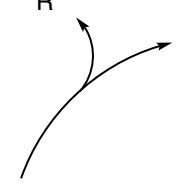

$[\mathrm{Pd}]^{*}$

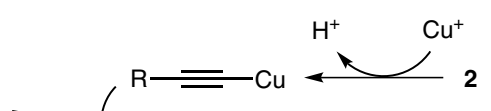

Selected examples:

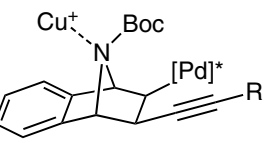

\section{$R$}

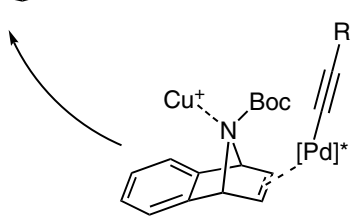

$\mathrm{R}=[\mathrm{Pd}]^{*}$

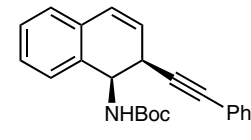

$97 \%$ yield $97 \%$ ee

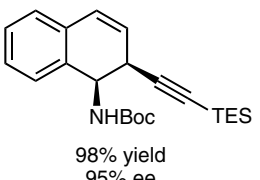

$95 \%$ ee

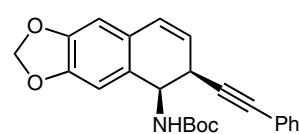

$89 \%$ yield $94 \%$ ee

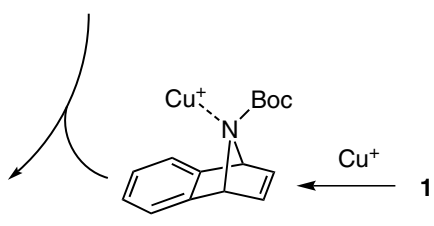

Significance: The ring opening of strained mesoheterobicyclic alkenes with different nucleophiles serves as a useful strategy for setting multiple stereocenters in a single transformation. Previous methods for this particular ring opening were limited to the use of bulky terminal acetylenes. Here, the authors report the development of a palladium and copper co-catalyzed system that exhibits broad substrate scope.
Comment: The authors propose that the copper(I) catalyst plays two distinct roles in the mechanism: (1) Copper facilitates transmetalation of the acetylene to palladium via the copper acetylide; (2) Copper behaves as a Lewis acid to activate the azabicyclic alkene. In addition to demonstrating wide functional group tolerance, the yields and enantioselectivities observed are excellent across the series of substrates tested.

SYNFACTS Contributors: Mark Lautens, Christine M. Le 